Article

\title{
Thermal Expansion Model of Cement Paste and Concrete Considering Micro-Structural Changes under Elevated Temperature
}

\author{
Jaesung Lee ${ }^{1}$, Yunping $\mathrm{Xi}^{2, *}$ and Seungcho Yang ${ }^{1}$ \\ 1 Department of Architectural Engineering, Hannam University, 70, Hannam-ro, Daedeok-gu, Daejeon, \\ Republic of Korea; jaesung@hnu.kr, ysj0785@naver.com \\ 2 Department of Civil Engineering, University of Colorado, Boulder, CO, 80309, USA \\ * Correspondence: Yunping.Xi@colorado.edu; Tel.: +1-303-492-8991 (Y. Xi)
}

\begin{abstract}
The expansion of concrete subjected to extreme elevated temperature is linked with intricate micro-structural variations, such as the transformation of the constituent phases. This study proposes a model to predict the thermal expansion of cement paste and concrete considering microstructural changes under elevated temperatures ranging from $20^{\circ} \mathrm{C}$ to $800^{\circ} \mathrm{C}$. The model presented can consider characteristics of various aggregates in the calculation of thermal expansion for concrete. The model is a combination of a multi-scale stoichiometric model and a multi-scale composite model. At the cement paste level, the model satisfactorily predicted a test result. At concrete level, upper bounds from the model were matched relatively well with test results by previous researcher. If the mechanical properties, such as elastic modulus (E), Poisson's ratio (v), and thermal deformation, of the aggregates used in concrete are given, it is likely that the model will reasonably predict experimental results.
\end{abstract}

Keywords: Phase change; Composite; Thermal expansion; High temperature; Concrete

\section{Introduction}

Under extreme elevated temperatures, concrete undergoes intricate physicochemical changes. Various studies of the constituents in concrete have been conducted to investigate essential causes for these physiochemical changes on different scales. In 1970, Harmathy considered theoretical models with experimental data that contained various thermal properties of cement paste, aggregates, and concrete under high temperature[1]. Harada et al., conducted experiments investigating the thermal properties with concrete containing aggregates of varying physical properties under high temperature[2]. Piasta conducted experiments for heat deformation of phases present in hardened cement paste for temperatures between $20-800^{\circ} \mathrm{C}[3]$. Piasta also studied studied the reactions of $\mathrm{Ca}(\mathrm{OH})_{2}, \mathrm{CaCO}_{3}$ (calcite), $\mathrm{C}-\mathrm{S}-\mathrm{H}$, non-evaporable water and micro-pores using thermal analysis (TA), X-ray diffraction analysis, infrared spectroscopy analysis and mercury porosity[4]. Cruz et al. conducted an experimental study for thermal expansion of Portland cement, mortar, and concrete[5]. These test results showed that the thermal strain of cement paste is greatly affected by the heating rate rather than curing age. Schneider and Herbst performed a study on the chemical reactions of the hydrate phase of hardened cement paste through elevated temperatures[6]. In a study conducted by Lin et al. the microstructure of concrete exposed to elevated temperatures in both actual fire and laboratory conditions were evaluated with the use of Scanning-Electron-Microscopy (SEM) and stereo microscopy. Wang et al. used SEM to examine the cracking of high performance concrete (HPC) exposed to high temperatures under axial compressive loading of about 200N[7]. Bastami et al. analyzed the thermal deformation of concrete at high temperature according to stress and temperature based on previous research results[8]. The parameters used in this experiment are the stress and heating temperature, the maximum stress of the concrete is $95 \mathrm{Mpa}$, and the maximum 
heating temperature is $700{ }^{\circ} \mathrm{C}$. As a result of comparing the thermal expansion of the concrete according to the temperature with the experimental value and the existing prediction formula, errors up to $20 \%$ were found. Hager conducted an experimental study for thermal expansion of concrete by type of aggregates (limestone, siliceous sand, basalt and calcareous quartz sand)[9]. These test results showed that the thermal strain of aggregates affected by the composition of aggregates.

However, despite various experimental studies, a thermal expansion model of concrete considering each phase transformation due increasing temperature from the micro-scale level has not yet been developed. This study proposes a model to predict the thermal expansion of cement paste and concrete considering micro-structural changes under elevated temperature ranging from $20^{\circ} \mathrm{C}$ to $800^{\circ} \mathrm{C}$. The model was obtained by combining a multi-scale stoichiometric model considering microstructural variations due to high temperature, and a multi-scale composite model proposed by $\mathrm{Xi}$ and Jennings[10].

\section{The Volume Fraction of Concrete Constituent Phase at Elevated Temperature}

Thermal expansion prediction model of concrete at high temperature is determined by combining a multi-scale stochastic model and a multi-scale composite model. This section briefly describes the multi-scale stoichiometry model used to predict the thermal expansion of concrete with increasing temperature. The multi-scale stoichiometry model of concrete with temperature rise proposed by Lee[11] was used to predict the modulus of elasticity of concrete at high temperatures. Properties of concrete decreases with increasing temperature. The main cause of this phenomenon is caused by two main mechanisms. The first one is related to the temperature sensitivity of the mechanical and thermal properties of the constituents in concrete. Thermal expansion or stiffness of each constituent decreases with increasing temperature, which leads to the degradation of the composite. The second mechanism is related to phase transformations of constituents at different temperatures. The initial constituents of concrete transform to other phases due to elevated temperature. The new phases tend to have lower stiffness than the original phases. Therefore, Lee analyzed the physical and chemical behavior under high temperature. In this study, the thermal expansion of concrete was predicted by Lee's model which is the volume faction of concrete constituent phase at elevated temperature. This chapter briefly explains the prediction of volume factions of the concrete constituent phase at elevated temperature.

In order to predict the phase change of the cement paste at high temperature, the initial volume fraction of components with mixing ration should be calculated. The total volume in expressed by Equation (1)

$$
V_{\text {level_c } \_ \text {to }}^{\text {total }}=V_{w}(t)+\sum_{i} V_{i}^{c k}(t)+V_{C-S-H}(t)+V_{C H}(t)+V_{A L}(t)+V_{\text {capillary voids }}(t)
$$

$V_{w}$ is the volume of the remaining water, determined by subtraction of the water consumed during hydration from the initial water content. $V_{i}^{c k}$ is the volume of the hydrated clinker phases in the cement, determined by the clinker of hydration degree. $C-S-H$ and $C H$ are produced by the hydration of $C_{3} S$ and $C_{2} S . V_{C-S-H}$ and $V_{C H}$ is determined by the hydration of $C_{3} S$ and $C_{2} S$. $V_{\text {level_c.p }}^{\text {total }}$ is calculated from the initial volume of the cement and water in the mixture because the value is constant with time. The volume fraction occupied by aluminates is calculated from Equation (2) and (3)

$$
\begin{gathered}
f_{i}=\frac{V_{i}}{V_{\text {level_col } \text { to }}^{\text {tol }}}=\frac{V_{i}}{V_{c}^{o}+V_{w}^{o}} \\
f_{A L}=1-\left(f_{C-S-H}+\sum_{i} f_{i}^{c k}+f_{C H}+f_{w}+f_{\text {capillary voids }}\right)
\end{gathered}
$$

The volume fraction of the constituent phase at the mortar and concrete levels are related to the mass proportions of the concrete mix design. At the mortar level, the volume fractions of the cement 
paste and sand can be calculated from Equation (4). The volume fraction at the concrete level are obtained by considering the coarse aggregate and the mortar in Equation (5).

$$
\begin{gathered}
f_{s}=\frac{f_{s}^{o}}{f_{c}^{o}+f_{w}^{o}+f_{s}^{o}}=\frac{u_{s} / \rho_{s}}{u_{c} / \rho_{c}+u_{w} / \rho_{w}+u_{s} / \rho_{s}} ; f_{c p}=1-f_{s} \\
f_{g}=\frac{f_{g}^{o}}{f_{c}^{o}+f_{w}^{o}+f_{s}^{o}+f_{a}^{o}}=\frac{u_{g} / \rho_{g}}{u_{c} / \rho_{c}+u_{w} / \rho_{w}+u_{s} / \rho_{s}+u_{g} / \rho_{g}} ; f_{m}=1-f_{g}
\end{gathered}
$$

The initial volume fraction of constituents in concrete will change when the concrete is exposed to high temperature. The changes of the volume fractions can be characterized by considering the phase transformation in the concrete under different ranges of high temperature. However, it is difficult to calculate the phase transformations exactly with temperature increase. Lee formulated some hypothesis to predict the phase transformations in concrete under high temperature[11]. The hypothesis are based on the decomposition of constituents in concrete at elevated temperatures. Table 1 shows processes of decomposition depending on the temperature regime.

Table 1. Processes of decomposition depending on the temperature regime

\begin{aligned} & \hline Temperature \multicolumn{1}{c}{ Decomposition } \\ & \hline $20-120^{\circ} \mathrm{C}$ Evaporation of free water, Dehydration of C-S-H and Ettringite \\ & $120-400^{\circ} \mathrm{C}$ Dehydration of $\mathrm{C}-\mathrm{S}-\mathrm{H} \\ & 400-530^{\circ} \mathrm{C}$ Dehydration of $\mathrm{C}-\mathrm{S}-\mathrm{H}$, Dehydration of $\mathrm{CH} \\ & 530-640^{\circ} \mathrm{C}$ Dehydration of $\mathrm{C}-\mathrm{S}-\mathrm{H}$, Decomposition of poorly crystallized $\mathrm{CaCO}_{3} \\ & 640-800^{\circ} \mathrm{C}$ Dehydration of C-S-H, Decomposition of $\mathrm{CaCO}_{3} \\ &$\hline\end{aligned}

The theoretical formulas for the volume fraction of each phase considering temperature and $\mathrm{w} / \mathrm{c}$ ratio are obtained from schemes described by Lee[11]. Table 2 shows theoretical formulas for volume fraction change of each phase

Table 2. Theoretical formulas for volume fraction change of each phase

\begin{tabular}{clc}
\hline \multirow{2}{*}{ Temperature } & \multicolumn{1}{c}{ Formulas (\%) } \\
\cline { 2 - 3 } & \multicolumn{1}{c}{$\mathbf{w} / \mathbf{c}=\mathbf{0 . 5}$} & \multicolumn{1}{c}{$\mathbf{w} / \mathbf{c}=\mathbf{0 . 6 7}$} \\
\hline \multirow{2}{*}{$120^{\circ} \mathrm{C} \leq \mathrm{T} \leq 800^{\circ} \mathrm{C}$} & $f_{C_{3.4} S_{2} H_{3}}=-5.6848 \cdot 10^{-2} T+45.478483$ & $f_{C_{3.4} S_{2} H_{3}}=-4.7061 \cdot 10^{-2} T+37.648961$ \\
& $f_{C_{3.4} S_{2}}=4.2129 \cdot 10^{-2} T-5.055587$ & $f_{C_{3.4} S_{2}}=3.4876 \cdot 10^{-2} T-4.185224$ \\
& $f_{C_{3.4} S_{2} H_{3}}^{w}=1.4718 \cdot 10^{-2} T-1.766185$ & $f_{C_{3.4} S_{2} H_{3}}=1.2184 \cdot 10^{-2} T-1.462121$ \\
\hline \multirow{2}{*}{$400^{\circ} \mathrm{C} \leq \mathrm{T} \leq 530^{\circ} \mathrm{C}$} & $f_{C H}=-1.2086 \cdot 10^{-1} T+64.055915$ & $f_{C H}=-1.0005 \cdot 10^{-1} T+53.028124$ \\
& $f_{C a O}=5.5007 \cdot 10^{-2} T-22.003092$ & $f_{C a O}=4.5537 \cdot 10^{-2} T-18.215066$ \\
& $f_{C H}^{w}=6.5852 \cdot 10^{-2} T-26.340994$ & $f_{C H}^{w}=5.4515 \cdot 10^{-2} T-21.806160$ \\
\hline
\end{tabular}

At an elevated temperature, sand and gravel in the mortar or concrete expand. However, the expansion is small compared to the initial volume. Therefore, the total volume of aggregates is assumed to be constant in the calculation for the volume fractions of sand and gravels. The volume fractions of each phase with respect to temperature increase at the mortar and concrete levels are calculated with Equation (6) and (7).

$$
\begin{gathered}
f_{i^{\prime}-\text { mortar }}=f_{i} \cdot f_{c p_{-} \text {mortar }} ; f_{s_{-} \text {motar }}=f_{s} \text {, at mortar level } \\
f_{i_{-} \text {con }}=f_{i} \cdot f_{c p} \cdot f_{m} ; f_{s_{-} c o n}=f_{s} \cdot f_{m} ; f_{g_{-} c o n}=f_{g} \text {, at concrete level }
\end{gathered}
$$


In which, $f_{i}$ is the volume fraction for $\mathrm{C}_{3.4} \mathrm{~S}_{2} \mathrm{H}_{3}, \mathrm{CH}, \mathrm{AL}, \mathrm{C}_{3.4} \mathrm{~S}_{2}, \mathrm{CaO}$, and void_cement which changed with temperature increase at the cement paste level.

\section{A Multi-Scale Composite Model}

Concrete is a heterogeneous material in which constituents are distributed randomly. Thus, there is no exact solution in modeling material properties considering constituents in concrete. To simplify the internal structure of a material, composite models for effective properties have been developed. The three phase model developed by Cristensen was originally developed for elastic properties only[12,13], but Herve and Zauoi have shown that the model can be extended to nonlinear materials[14].

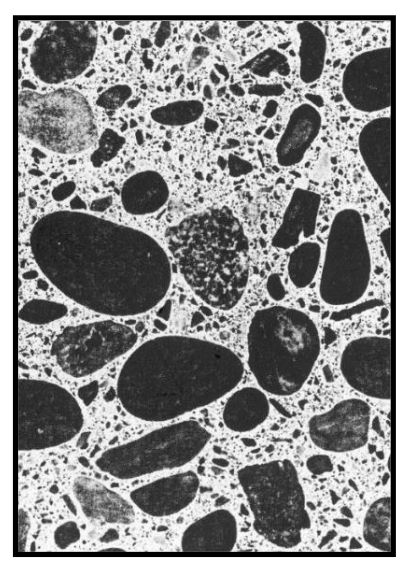

(a)

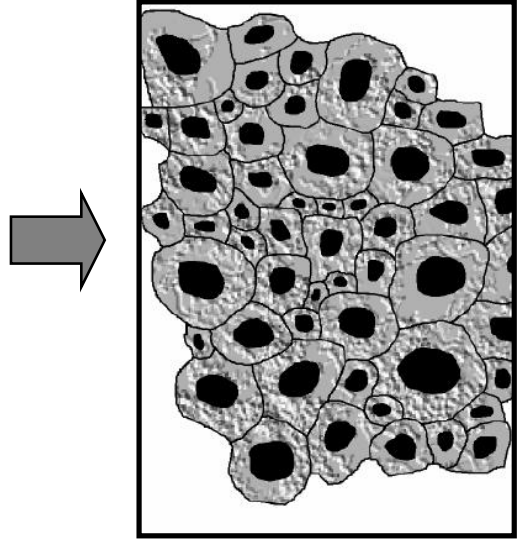

(b)

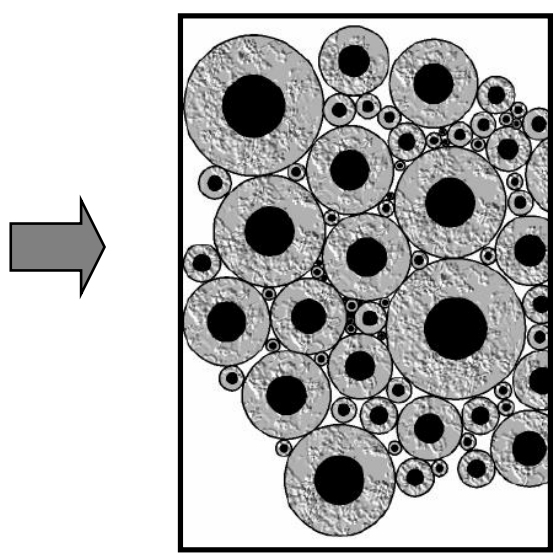

(c)

Figure 1. Simplification to spherical model. (a) Concrete, (b) Partitioning, (c) Spherical model

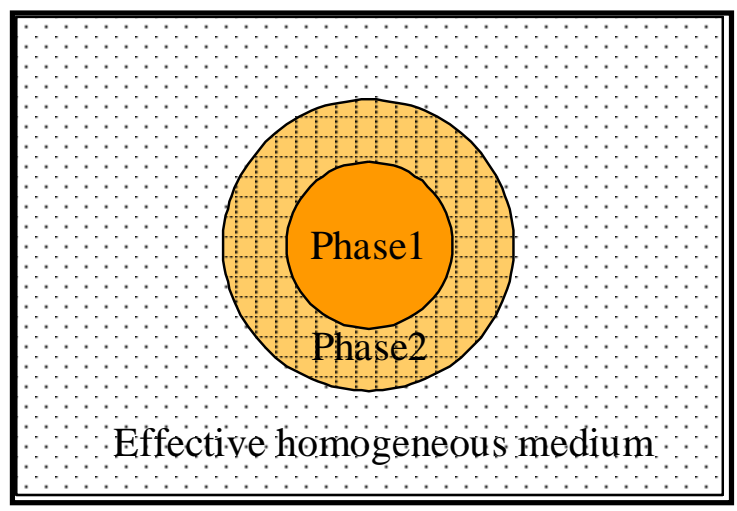

Figure 2. Three-phase effective media model

In Figure 1, the meso-structure of concrete (Figure 1a) can be expressed as Figure 1b by partitioning aggregate and matrix. In the spherical model the partitions are simplified using spherical elements, Figure 1c, such that the volume fraction of each phase and internal structure in an element are the same regardless of the size of elements. The spherical elements have three dimensional feathers, reducing the problem to one dimension[10]. On the nanometer and micrometer scales, the spherical model can be applied. Figure 2 shows the three-phase effective media model, where phase 3 is the effective homogeneous medium made equivalent to the heterogeneous medium.

$\mathrm{Xi}$ and Jennings proposed a model for shrinkage of cement paste and concrete using the effective homogeneous theory[10]. The proposed thermal expansion model is obtained by combining the multiscale composite model proposed by $\mathrm{Xi}$ and Jennings and the multi-scale stoichiometric model described in section 2. Although the model by $\mathrm{Xi}$ and Jennings is for shrinkage, it can also be used for effective 
thermal expansion in a heterogeneous medium. The effective bulk modulus and strain for the effective homogeneous phase shown in Figure 2 are expressed using Equation (8) and Equation (9)respectively.

$$
\begin{aligned}
& K_{\text {eff }}^{12}=K_{2}+\frac{\left(\frac{V_{1}}{V_{1}+V_{2}}\right) \cdot\left(K_{1}-K_{2}\right)}{1+\left(1-\frac{V_{1}}{V_{1}+V_{2}}\right) \cdot\left(\frac{K_{1}-K_{2}}{K_{2}+\frac{4}{3} G_{2}}\right)} \\
& \varepsilon_{\text {eff }}^{12}=\frac{K_{1} \varepsilon_{1}\left(\frac{V_{1}}{V_{1}+V_{2}}\right) \cdot\left(3 K_{2}+4 G_{2}\right)+K_{2} \varepsilon_{2}\left(1-\frac{V_{1}}{V_{1}+V_{2}}\right) \cdot\left(3 K_{1}+4 G_{2}\right)}{K_{2}\left(3 K_{2}+4 G_{2}\right)-4 G_{2} \cdot\left(\frac{V_{1}}{V_{1}+V_{2}}\right) \cdot\left(K_{2}-K_{1}\right)}
\end{aligned}
$$

In which, $K_{i}, V_{i}$ and $G_{i}$ are the bulk modulus, volume fraction, and shear modulus of phase $i$ , respectively. For multiphase, the effective bulk modulus and strain are delineated as Equation. (10), (11) and (12)[10].

$$
\begin{gathered}
\left(K_{\text {eff }}\right)_{i}=K_{i}+\frac{c_{i-1, i} \cdot\left[\left(K_{\text {eff }}\right)_{i-1}-K_{i}\right]}{1+\left(1-c_{i-1, i}\right) \cdot\left[\frac{\left(K_{\text {eff }}\right)_{i-1}-K_{i}}{\left.K_{i}+\frac{4}{3} G_{i}\right]}\right.} \\
\left(\varepsilon_{\text {eff }}\right)_{i}=\frac{\left(K_{\text {eff }}\right)_{i-1}\left(\varepsilon_{\text {eff }}\right)_{i-1} c_{i-1, i}\left(3 K_{i}+4 G_{i}\right)+K_{i} \varepsilon_{i}\left(1-c_{i-1, i}\right) \cdot\left[4 G_{i}+3\left(K_{\text {eff }}\right)_{i-1}\right]}{K_{i}\left[3\left(K_{\text {eff }}\right)_{i-1}+4 G_{i}\right]-4 c_{i-1, i} G_{i} \cdot\left[K_{i}-\left(K_{\text {eff }}\right)_{i-1}\right]}
\end{gathered}
$$

where $N \geq i \geq 2 ;\left(K_{\text {eff }}\right)_{1}=K_{1}$ and $\left(\varepsilon_{\text {eff }}\right)_{1}=\varepsilon_{1}$.

Parameter $c_{i-1, i}$ is:

$$
c_{i-1, i}=\sum_{j=1}^{i-1} V_{j} / \sum_{j=1}^{i} V_{j} \text { for } N>i \geq 2 \text { and } c_{N-1, N}=\sum_{j=1}^{N-1} V_{j}=1-V_{N} \text { for } i=N
$$

The parameters $G_{i}$ and $K_{i}$ can be expressed easily in terms of elastic modulus and Poisson's ratio. From elastic theory, $K_{i}=E_{i} / 3\left(1-2 v_{i}\right)$ and $G_{i}=E_{i} / 2\left(1+v_{i}\right)$.

\section{Material Properties of Constituents}

To predict thermal expansion the information for the stiffness, Poisson's ratio, and thermal expansion of each phase should be given.

Experimental studies for heat deformations of cement paste were performed[3]. Thermal strains of dehydrated and hydrated substances were measured using the dilatometer. The samples for the test were sleeve shaped with an inner diameter of $5 \mathrm{~mm}$, an outer diameter of $10 \mathrm{~mm}$, and a height of $50 \mathrm{~mm}$. The dehydrated samples were compacted imparting a pressure of 40Mpa. Paste samples were prepared with a w/c ratio of 0.5 and compacted by means of vibration. The investigation into heat deformation of the dehydrated substances was performed directly after forming. The paste samples were examined after curing for 28 days under a relative humidity of $95 \%$ and a temperature of $20 \pm 2{ }^{\circ} \mathrm{C}$. A heating rate of $10^{\circ} \mathrm{C} / \mathrm{min}$ was used to measure heat deformation for all substances. Thermal strain of $\mathrm{CaO}$ (decomposed from $\mathrm{CH}$ ), was calculated using the test data from the coefficient of thermal expansion [15]. Figure 3 and Figure 4 are the test data regarding thermal strains of dehydrated and hydrated substances respectively. 


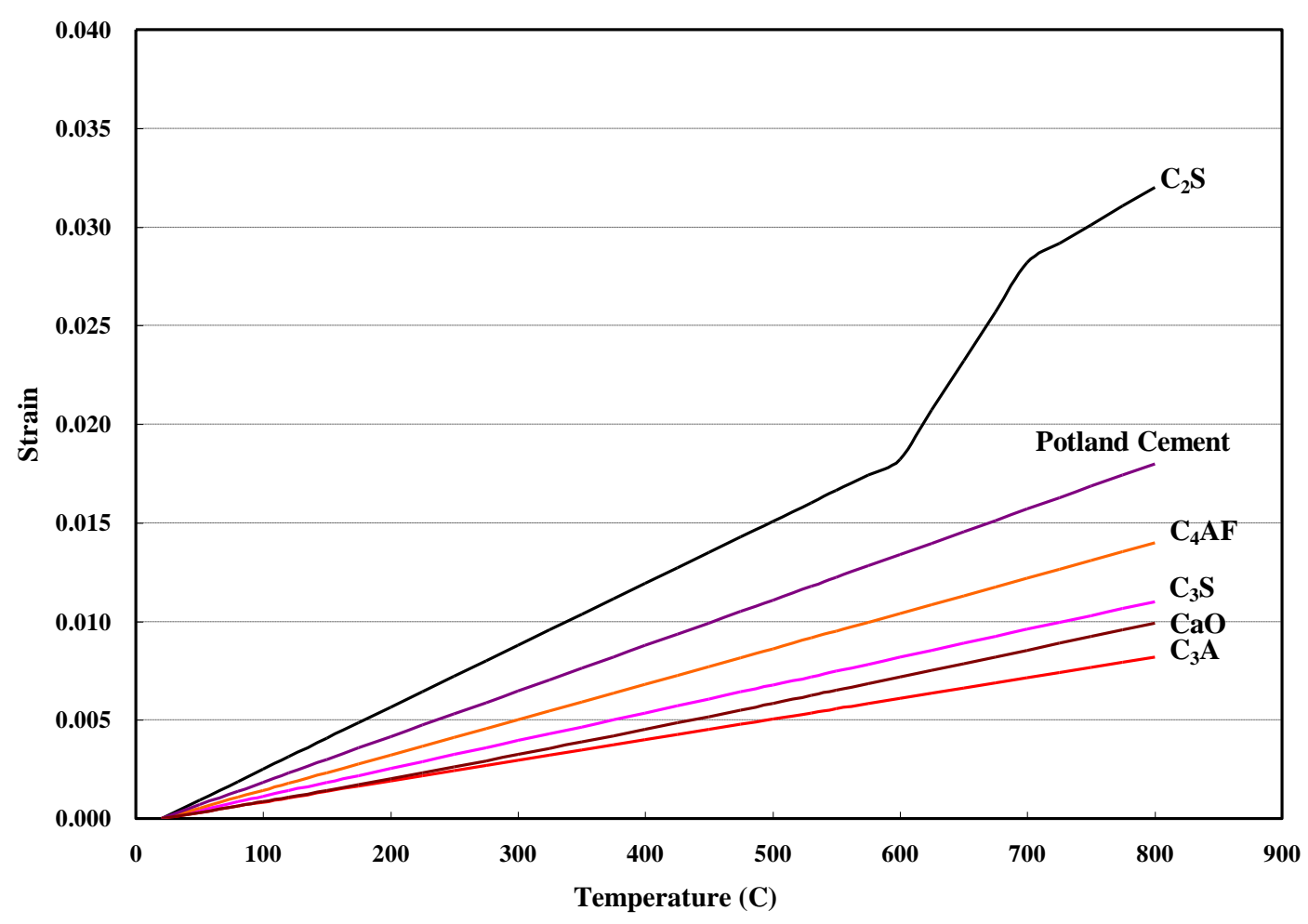

Figure 3. Thermal strain test data of dehydrated substances

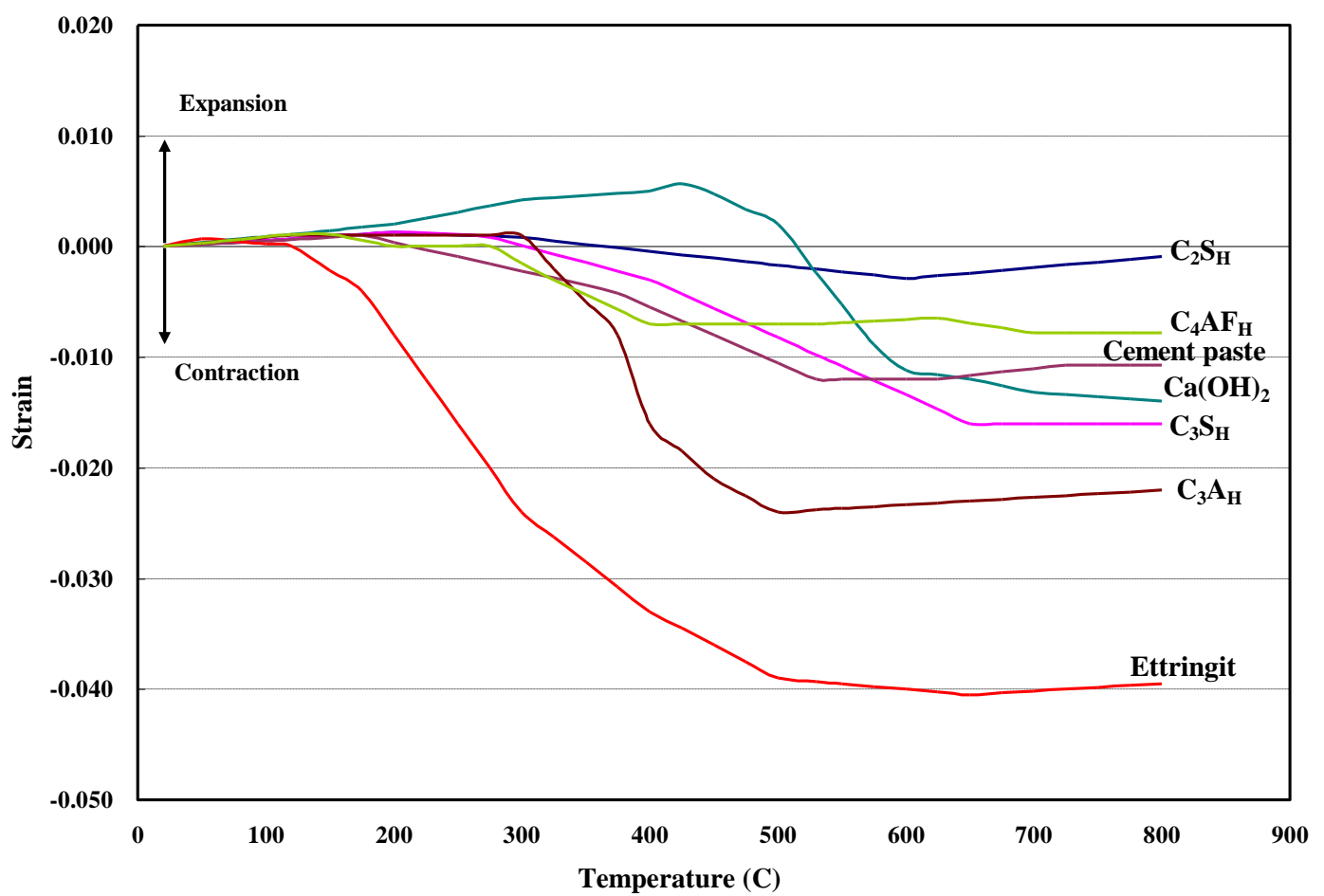

Figure 4. Thermal strain test data of hydrated substances

Generally up to $150^{\circ} \mathrm{C}$ hydrate substances expand because the expansion in the dehydrated parts is more prevalent than the shrinkage of hydrated parts[3]. At temperatures above $150^{\circ} \mathrm{C}$ shrinkage prevails due to dehydration.

In phases considered for the model at the cement paste level are $\mathrm{C}_{3.4} \mathrm{~S}_{2} \mathrm{H}_{3}, \mathrm{C}_{3.4} \mathrm{~S}_{2}, \mathrm{CH}, \mathrm{CaO}$, aluminum hydrates, and void space. The test data of $\mathrm{CH}$ and $\mathrm{CaO}$ shown in Figure 3 are used in the model. However, because there is no exact information for the thermal strain of the chemical components $C_{3.4} S_{2}$ and $C_{3.4} S_{2} H_{3}$ from literatures, the average thermal strain of $C_{2} S_{H}$ and $C_{3} S_{H}$ 
are shown in Figure 4 and is used as the thermal strain for $C_{3.4} S_{2} H_{3}$. The thermal stain of $C_{3.4} S_{2}$ is assumed on the basis of the test data for $\mathrm{C}_{2} S$ and $\mathrm{C}_{2} S$ in Figure 3.

In the model, the thermal strain for alumina hydrates should be considered because the thermal deformations of alumina hydrates, i.e. ettringite and $C_{3} A_{H}$ are large compared to other components, shown in Figure 4. In cement paste, alumina hydrates exist in various chemical components which make it difficult to create a model that contains the all chemical components for alumina hydrates. Usually, the hydration of $C_{3} A$ and $C_{3} A F$ in Portland cement involve reactions with sulfate ions which are supplied by the dissolution of gypsum. The primary reactions of $C_{3} A$ and $C_{3} A F$ are expressed with Equation. (13) and (14) respectively[16]

$$
\begin{aligned}
& C_{3} A+3 C \overline{S_{S}} H_{2}(\text { gypsum })+26 H \rightarrow C_{6} A \overline{S_{3}} H_{32}(\text { ettringite }) \\
& C_{4} A F+3 C \bar{S} H_{2}(\text { gypsum })+21 H \rightarrow C_{6}(A, F) \overline{S_{3}} H_{32}+(A, F) H_{3}
\end{aligned}
$$

Ettringite is the first hydrate to crystallize because of the high ratio of sulfate to aluminates in the solution phase during the first hour of hydration. In Portland cement, which contains 5-6 percent gypsum, ettringite contributes to early strength development. After the depletion of sulfate when the aluminate concentration goes up again due to renewed hydration of $C_{3} A$ and $C_{4} A F$, ettringite becomes unstable and is gradually converted into monosulfate, the final product[17]. Equation. (15) contains the chemical reaction from ettringite to monosulfate. Equation. (16) shows the chemical reaction converted from $C_{6}(A, F) \overline{S_{3}} H_{32}$ to $3 C_{4}(A, F) \bar{S} H_{12}$.

$$
\begin{aligned}
& C_{6} A \overline{S_{3}} H_{32} \text { (ettringite) }+2 C_{3} A+4 H \rightarrow 3 C_{4} A \bar{S} H_{12} \text { (monosulfate) } \\
& C_{6}(A, F) \overline{S_{3}} H_{32}+C_{4} A F+7 H \rightarrow 3 C_{4}(A, F) \bar{S} H_{12}+(A, F) H_{3}
\end{aligned}
$$

In Equation. (14) and Equation. (16), iron oxide plays the same role as alumina during hydration. $\mathrm{F}$ can substitute for $\mathrm{A}$ in the hydration products. The use of a formula such as $C_{6}(A, F) \overline{S_{3}} H_{32}$ indicates that iron oxide and alumina occur interchangeably in the compound, but the $\mathrm{A} / \mathrm{F}$ ratio need not be the same as that of the parent compound. When monosulfate comes in contact with a new source of sulfate ions ettringite can be formed once again. This potential for reforming ettringite is the basis for sulfate attack on Portland cement[16]. In the current model alumina hydrates are assumed as monosulfate. However, the information for thermal strain of monosulfate could not be found from literatures. As a matter of fact, there is no known mineral of monosulfate. Thus, the thermal strain of the monosulfate is assumed on the basis of the test data of $C_{3} A_{H}$ and ettringite shown in Figure 4. Table 3 is a summary for thermal strain functions according to the temperature range of each phase in cement paste used in the model. Figure 5 is a plot for the thermal strains of phases from the functions. 


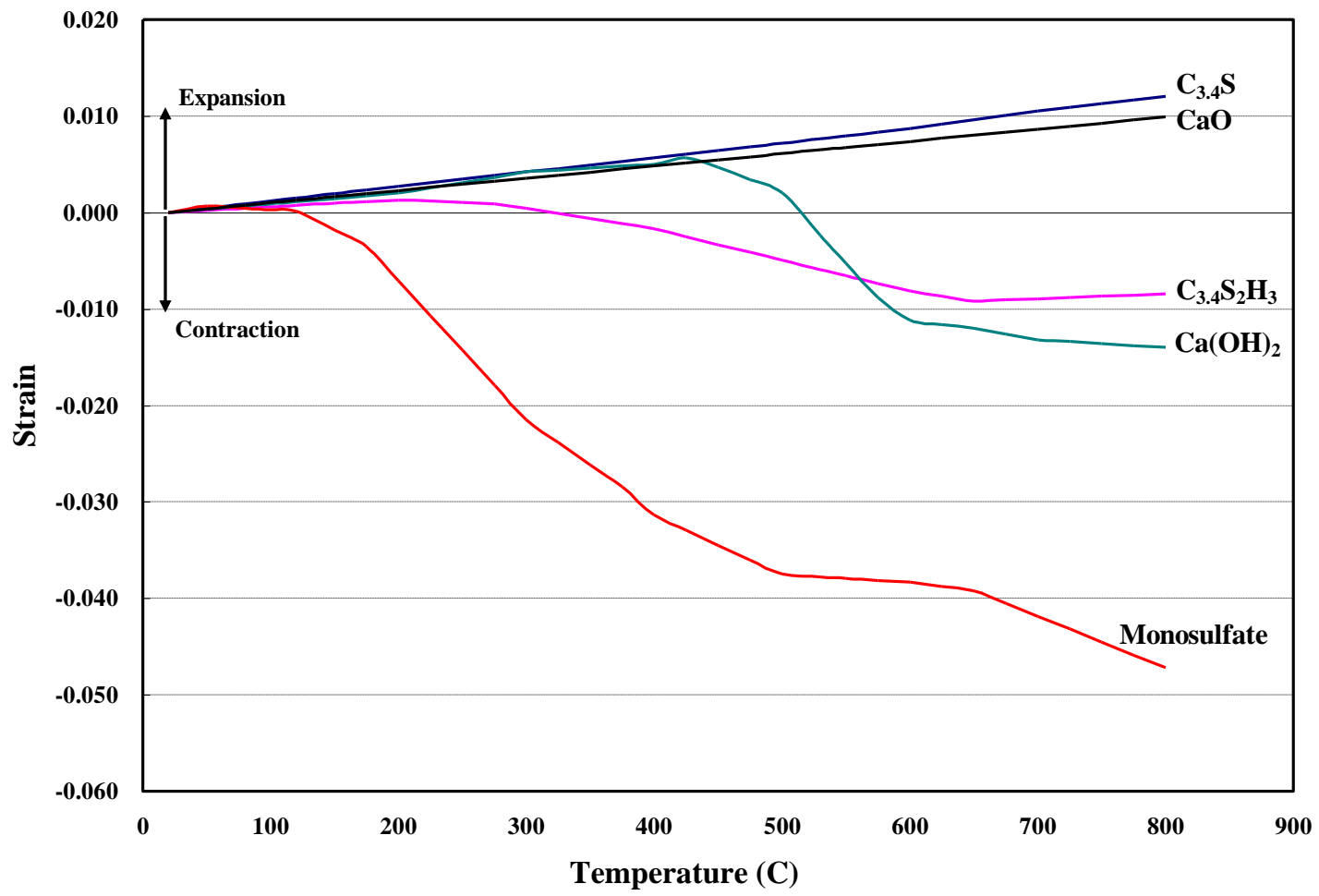

Figure 5. Thermal strains of phases in cement paste used in model 
Table 3. Summary for thermal strain of phases in cement paste used in model

\begin{tabular}{|c|c|c|}
\hline Phase & Temperature & Strain \\
\hline \multirow{3}{*}{$C_{3.4} S_{2}$} & $20^{\circ} \mathrm{C}<\mathrm{T} \leq 600^{\circ} \mathrm{C}$ & $\varepsilon=1.49664 \cdot 10^{-5} T-2.99328 \cdot 10^{-4}$ \\
\hline & $600^{\circ} \mathrm{C}<\mathrm{T} \leq 700^{\circ} \mathrm{C}$ & $\varepsilon=1.83974 \cdot 10^{-5} T-2.35795 \cdot 10^{-3}$ \\
\hline & $700^{\circ} \mathrm{C}<\mathrm{T} \leq 800^{\circ} \mathrm{C}$ & $\varepsilon=1.52974 \cdot 10^{-5} T-1.87949 \cdot 10^{-4}$ \\
\hline $\mathrm{CaO}$ & $20^{\circ} \mathrm{C}<\mathrm{T} \leq 800^{\circ} \mathrm{C}$ & $\varepsilon=1.26923 \cdot 10^{-5} T-2.538462 \cdot 10^{-4}$ \\
\hline \multirow{7}{*}{$\mathrm{C}_{3.4} \mathrm{~S}_{2} \mathrm{H}_{3}$} & $20^{\circ} \mathrm{C}<\mathrm{T} \leq 200^{\circ} \mathrm{C}$ & $\varepsilon=7.22222 \cdot 10^{-6} T-1.44444 \cdot 10^{-4}$ \\
\hline & $200^{\circ} \mathrm{C}<\mathrm{T} \leq 270^{\circ} \mathrm{C}$ & $\varepsilon=-4.64286 \cdot 10^{-6} T+2.222857 \cdot 10^{-3}$ \\
\hline & $270^{\circ} \mathrm{C}<\mathrm{T} \leq 300^{\circ} \mathrm{C}$ & $\varepsilon=-1.78846 \cdot 10^{-5} T+5.80385 \cdot 10^{-3}$ \\
\hline & $300^{\circ} \mathrm{C}<\mathrm{T} \leq 400^{\circ} \mathrm{C}$ & $\varepsilon=-2.15513 \cdot 10^{-5} T+6.90385 \cdot 10^{-3}$ \\
\hline & $400^{\circ} \mathrm{C}<\mathrm{T} \leq 600^{\circ} \mathrm{C}$ & $\varepsilon=-3.21667 \cdot 10^{-5} T+1.115 \cdot 10^{-2}$ \\
\hline & $600^{\circ} \mathrm{C}<\mathrm{T} \leq 650^{\circ} \mathrm{C}$ & $\varepsilon=-2.1 \cdot 10^{-5} T+4.45 \cdot 10^{-3}$ \\
\hline & $650^{\circ} \mathrm{C}<\mathrm{T} \leq 800^{\circ} \mathrm{C}$ & $\varepsilon=5 \cdot 10^{-6} T-1.245 \cdot 10^{-2}$ \\
\hline \multirow{9}{*}{$\mathrm{CH}$} & $20^{\circ} \mathrm{C}<\mathrm{T} \leq 200^{\circ} \mathrm{C}$ & $\varepsilon=1.11111 \cdot 10^{-5} T-2.22222 \cdot 10^{-4}$ \\
\hline & $200^{\circ} \mathrm{C}<\mathrm{T} \leq 300^{\circ} \mathrm{C}$ & $\varepsilon=2.2 \cdot 10^{-5} T-2.4 \cdot 10^{-3}$ \\
\hline & $300^{\circ} \mathrm{C}<\mathrm{T} \leq 400^{\circ} \mathrm{C}$ & $\varepsilon=8.0 \cdot 10^{-6} T+1.8 \cdot 10^{-3}$ \\
\hline & $400^{\circ} \mathrm{C}<\mathrm{T} \leq 430^{\circ} \mathrm{C}$ & $\varepsilon=2.66667 \cdot 10^{-5} T-5.66667 \cdot 10^{-3}$ \\
\hline & $430^{\circ} \mathrm{C}<\mathrm{T} \leq 500^{\circ} \mathrm{C}$ & $\varepsilon=-5.42857 \cdot 10^{-5} T+2.91429 \cdot 10^{-2}$ \\
\hline & $500^{\circ} \mathrm{C}<\mathrm{T} \leq 590^{\circ} \mathrm{C}$ & $\varepsilon=-1.44444 \cdot 10^{-4} T+7.42222 \cdot 10^{-2}$ \\
\hline & $590^{\circ} \mathrm{C}<\mathrm{T} \leq 650^{\circ} \mathrm{C}$ & $\varepsilon=-1.66667 \cdot 10^{-5} T-1.16667 \cdot 10^{-3}$ \\
\hline & $650^{\circ} \mathrm{C}<\mathrm{T} \leq 700^{\circ} \mathrm{C}$ & $\varepsilon=-2.4 \cdot 10^{-5} T+3.6 \cdot 10^{-3}$ \\
\hline & $700^{\circ} \mathrm{C}<\mathrm{T} \leq 800^{\circ} \mathrm{C}$ & $\varepsilon=-8.0 \cdot 10^{-6} T-7.6 \cdot 10^{-3}$ \\
\hline \multirow{11}{*}{$\begin{array}{c}3 C_{4} A \bar{S} H_{12} \\
\text { (Monosulfate) }\end{array}$} & $20^{\circ} \mathrm{C}<\mathrm{T} \leq 50^{\circ} \mathrm{C}$ & $\varepsilon=2.2 \cdot 10^{-5} T-4.4 \cdot 10^{-4}$ \\
\hline & $50^{\circ} \mathrm{C}<\mathrm{T} \leq 120^{\circ} \mathrm{C}$ & $\varepsilon=-8.0 \cdot 10^{-6} T+1.06 \cdot 10^{-3}$ \\
\hline & $120^{\circ} \mathrm{C}<\mathrm{T} \leq 175^{\circ} \mathrm{C}$ & $\varepsilon=-6.54545 \cdot 10^{-5} T+7.95455 \cdot 10^{-3}$ \\
\hline & $175^{\circ} \mathrm{C}<\mathrm{T} \leq 300^{\circ} \mathrm{C}$ & $\varepsilon=-1.44 \cdot 10^{-4} T+2.17 \cdot 10^{-2}$ \\
\hline & $300^{\circ} \mathrm{C}<\mathrm{T} \leq 375^{\circ} \mathrm{C}$ & $\varepsilon=-9.3 \cdot 10^{-5} T+6.4 \cdot 10^{-3}$ \\
\hline & $375^{\circ} \mathrm{C}<\mathrm{T} \leq 400^{\circ} \mathrm{C}$ & $\varepsilon=-1.13 \cdot 10^{-4} T+1.39 \cdot 10^{-2}$ \\
\hline & $400^{\circ} \mathrm{C}<\mathrm{T} \leq 450^{\circ} \mathrm{C}$ & $\varepsilon=-6.4 \cdot 10^{-5} T-5.7 \cdot 10^{-3}$ \\
\hline & $450^{\circ} \mathrm{C}<\mathrm{T} \leq 500^{\circ} \mathrm{C}$ & $\varepsilon=-6.0 \cdot 10^{-5} T-7.5 \cdot 10^{-3}$ \\
\hline & $500^{\circ} \mathrm{C}<\mathrm{T} \leq 600^{\circ} \mathrm{C}$ & $\varepsilon=-8.33333 \cdot 10^{-6} T-3.33333 \cdot 10^{-2}$ \\
\hline & $600^{\circ} \mathrm{C}<\mathrm{T} \leq 650^{\circ} \mathrm{C}$ & $\varepsilon=-1.73333 \cdot 10^{-5} T-2.79333 \cdot 10^{-2}$ \\
\hline & $650^{\circ} \mathrm{C}<\mathrm{T} \leq 800^{\circ} \mathrm{C}$ & $\varepsilon=-5.33333 \cdot 10^{-5} T-4.53333 \cdot 10^{-3}$ \\
\hline
\end{tabular}


Table 4. Elastic properties of each phase

\begin{tabular}{|c|c|c|c|}
\hline Phases & $E(G p a)$ & $v(-)$ & References \\
\hline \multirow{2}{*}{$\mathrm{CSH}$} & $31 \pm 4$ & - & Acker (2001) \\
\hline & $29.4 \pm 2.4$ & 0.24 & Constantinides and Ulm (2004) \\
\hline \multirow{2}{*}{$C_{3} S$} & $147 \pm 5$ & 0.3 & Acker (2001) \\
\hline & $135 \pm 7$ & 0.3 & Velez et al. (2001) \\
\hline \multirow{2}{*}{$C_{2} S$} & $140 \pm 10$ & 0.3 & Acker (2001) \\
\hline & $130 \pm 20$ & 0.3 & Velez et al. (2001) \\
\hline \multirow{5}{*}{$\mathrm{CH}$} & 35.24 & - & Beaudoin (1983) \\
\hline & 48 & - & Wittmann (1986) \\
\hline & $39.77-44.22$ & $0.305-0.325$ & Monteriro and Chang \\
\hline & $36 \pm 3$ & - & Acker (2001) \\
\hline & $38 \pm 5$ & - & Constantinides and Ulm (2004) \\
\hline $\mathrm{CaO}$ & $194.54 \pm 0.5$ & 0.207 & Oda et al. (1992) \\
\hline \multirow{2}{*}{$C_{3} A$} & $160 \pm 10$ & - & Acker (2001) \\
\hline & $145 \pm 10$ & - & Velez et al. (2001) \\
\hline$C_{3} A F$ & $125 \pm 25$ & - & Velez et al. (2001) \\
\hline
\end{tabular}

Table 4 is a summary of the elastic properties of the phases obtained from literatures. It is noticed that the elastic modulus of $\mathrm{CS}$ decomposed from $\mathrm{C}-\mathrm{S}-\mathrm{H}$ and $\mathrm{CaO}$ decomposed from $\mathrm{CH}$ vary depending on the porosity of the phase. The porosity of $\mathrm{CaO}$ and $\mathrm{C}_{3.4} \mathrm{~S}_{2}$ are calculated using the volume fractions of phases decomposed from $\mathrm{CH}$ and $\mathrm{C}_{3.4} \mathrm{~S}_{2} \mathrm{H}_{3}$. The functions are shown in Equation. (17).

$$
p_{\mathrm{CaO}}=\frac{V_{\mathrm{H}_{2} \mathrm{O}_{-} \mathrm{CH}}}{V_{\mathrm{CaO} \_\mathrm{CH}}+V_{\mathrm{H}_{2} \mathrm{O}_{-} \mathrm{CH}}} ; \quad p_{\mathrm{C}_{3.4} \mathrm{~S}_{2}}=\frac{V_{\mathrm{H}_{2} \mathrm{O}_{-} \mathrm{C}_{3.4} \mathrm{~S}_{2} \mathrm{H}_{3}}}{V_{\mathrm{C}_{3.4} \mathrm{~S}_{2} \mathrm{C}_{3.4} \mathrm{~S}_{2} \mathrm{H}_{3}}+V_{\mathrm{H}_{2} \mathrm{O}_{-} \mathrm{C}_{3.4} \mathrm{~S}_{2} \mathrm{H}_{3}}}
$$

Table 5. Elastic modulus of each phase used in the current model

\begin{tabular}{ccc}
\hline Phases & $\boldsymbol{p}_{\boldsymbol{i}}$ (Porosity) & $\boldsymbol{E}$ (Gpa ) \\
\hline$C_{3.4} S_{2} H_{3}$ & - & 32.0 \\
\hline$C_{3.4} S_{2}$ & 0.26 & $29.79\left[\right.$ from $\left.E=120 \cdot\left(1-p_{C_{3.4} S_{2}}\right)^{n}, \mathrm{n}=4.65\right]$ \\
\hline$C H$ & - & 40.2 \\
\hline$C a O$ & 0.54 & $8.35\left[\right.$ from $\left.E=194.54 \cdot\left(1-p_{C a O}\right)^{n}, \mathrm{n}=4\right]$ \\
\hline Monosulfate & 0.25 & 40.0 \\
\hline Void & - & 0 \\
\hline
\end{tabular}

Table 5 shows the elastic modulus of phases used in the model. The functions for the elastic modulus of $\mathrm{CaO}$ and $\mathrm{C}_{3.4} \mathrm{~S}_{2}$ with respect to porosity are modified in the basis of empirical functions by Velez et al[18]. The fixed variable (n) in the function, on Table 5, for the elastic modulus of $\mathrm{CaO}$ is assumed as 4, which is an average value for variables used in the functions for $C_{2} S$ and $C_{2} A$. The elastic modulus and Poisson's ratio for monosulfate are assumed as $4 G p a$ and 0.25 respectively. Generally, the volume portion of aggregates is between $65 \%$ and $80 \%$ of the total volume of concrete. Therefore, they have a very important effect on the volume changes of concrete. The material properties 
of various aggregates are summarized in Table 6. It should be noticed that there are no consistency for the properties in the Table 6 because the chemical portions consisting rocks are different each other, even if the rocks are called with the same name.

Table 6. Elastic properties of various aggregates (Jumijis, 1983)

\begin{tabular}{|c|c|c|c|}
\hline \multicolumn{2}{|c|}{ Rock } & \multirow{2}{*}{$\frac{\boldsymbol{E}(\boldsymbol{G p a})}{19.1-111.5}$} & \multirow{2}{*}{$\frac{v(-)}{0.14-0.25}$} \\
\hline \multirow{5}{*}{ Igneous rocks } & Basalt & & \\
\hline & Diabase & $22.0-114.0$ & $0.103-0.333$ \\
\hline & Gabbro & $58.4-107.8$ & $0.125-0.48$ \\
\hline & Granite & $21.3-68.5$ & $0.125-0.338$ \\
\hline & Syenite & $58.8-86.3$ & $0.15-0.319$ \\
\hline \multirow{4}{*}{ Sedimentary rocks } & Dolomite & 19.6-93.0 & $0.08-0.37$ \\
\hline & Limestone & $8.0-78.5$ & $0.10-0.33$ \\
\hline & Sandstone & $4.9-84.5$ & $0.066-0.62$ \\
\hline & Shale (clay) & $7.8-44.0$ & $0.04-0.54$ \\
\hline \multirow{5}{*}{ Metamorphic } & Gneiss & $14.2-70.0$ & $0.091-0.25$ \\
\hline & Marble & $28.0-100.0$ & $0.11-0.38$ \\
\hline & Quartzite & 25.5-97.5 & $0.11-0.23$ \\
\hline & Schist & $4.0-70.5$ & $0.01-0.20$ \\
\hline & Slate & - & $0.06-0.44$ \\
\hline
\end{tabular}

Table 7 shows the thermal strain functions of sandstone and limestone obtained from curve fitting of test data by Soles and Geller[19].

Table 7. Summary for thermal strain of limestone and sandstone

\begin{tabular}{cll}
\hline Phase & Temperature & \multicolumn{1}{c}{ Strain } \\
\hline \multirow{2}{*}{ Sandstone } & $20^{\circ} \mathrm{C}<\mathrm{T} \leq 600^{\circ} \mathrm{C}$ & $\varepsilon=4.0 \times 10^{-14} \cdot T^{4}-2.0 \times 10^{-11} T^{3}+2.0 \times 10^{-8} T^{2}+9.0 \times 10^{-6} T-0.0002$ \\
& $600^{\circ} \mathrm{C}<\mathrm{T} \leq 650^{\circ} \mathrm{C}$ & $\varepsilon=1.75 \cdot 10^{-5} T+2.625 \cdot 10^{-3}$ \\
& $650^{\circ} \mathrm{C}<\mathrm{T} \leq 800^{\circ} \mathrm{C}$ & $\varepsilon=3.80 \cdot 10^{-6} T+1.153 \cdot 10^{-2}$ \\
\hline Limestone & $20^{\circ} \mathrm{C}<\mathrm{T} \leq 800^{\circ} \mathrm{C}$ & $\varepsilon=4.0 \times 10^{-12} T^{3}+1.0 \times 10^{-8} T^{2}+9.0 \times 10^{-6} T-0.0003$ \\
\hline
\end{tabular}

\section{Comparison between model and experimental results}

To apply the multi-scale composite model, arrangement of the phases in cement paste is shown in Figure 6. 


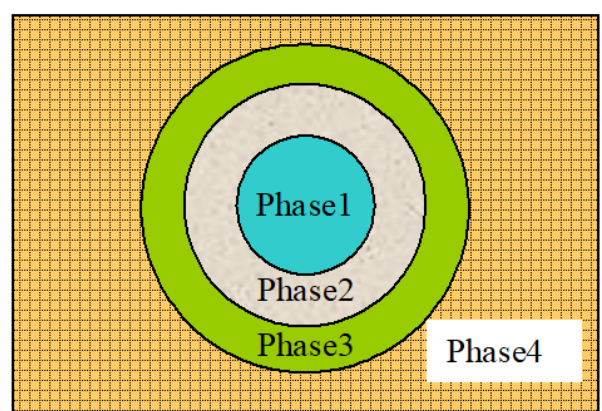

Phase 1: Void

Phase 2: Crystal Phases

(CH \& Monosulfate)

Phase 3: Gel Phase (CSH)

Phase 4: Cement paste

(Effective medium)

Temperature increase (Decomposition of Phases)

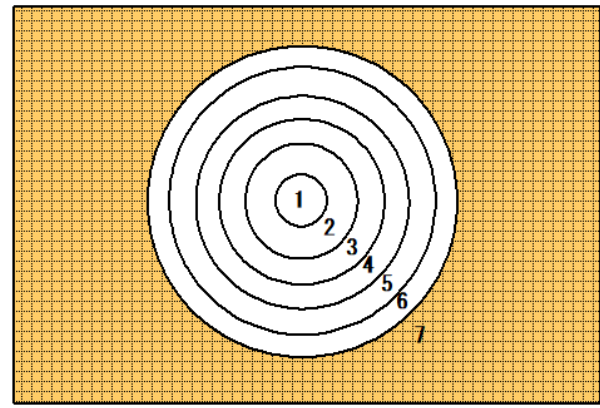

Phase 1: Void

Phase 2: $\mathrm{CaO}$

Phase 3: $\mathrm{CH}$

Phase 4: Monosulafate

Phase 5: CS

Phase 6: $\mathrm{CSH}$

Phase 7: Cement paste

(Effective medium)

Figure 6. Arrangement of phases in cement paste

Before cement paste is exposed to high temperature, void and crystal phases are surrounded by gel phase. When cement paste are exposed to high temperature, the decomposed solid phases, ie $\mathrm{CaO}$ from $\mathrm{CH}$ and $\mathrm{C}_{3.4} \mathrm{~S}_{2}$ from $\mathrm{C}_{3.4} \mathrm{~S}_{2} \mathrm{H}_{3}$ are located in close proximity to primary phases and the decomposed voids from $\mathrm{C}_{3.4} \mathrm{~S}_{2} \mathrm{H}_{3}$ and $\mathrm{CH}$ are located at the center of cement paste in the model. The model is obtained by combination of the multi-scale composite model considering the arrangement for phases shown in Figure 6 and the multi-scale stoichiometric model described in section 2, is compared with the test result in Figure 7. The model satisfactorily predicts the test result. 


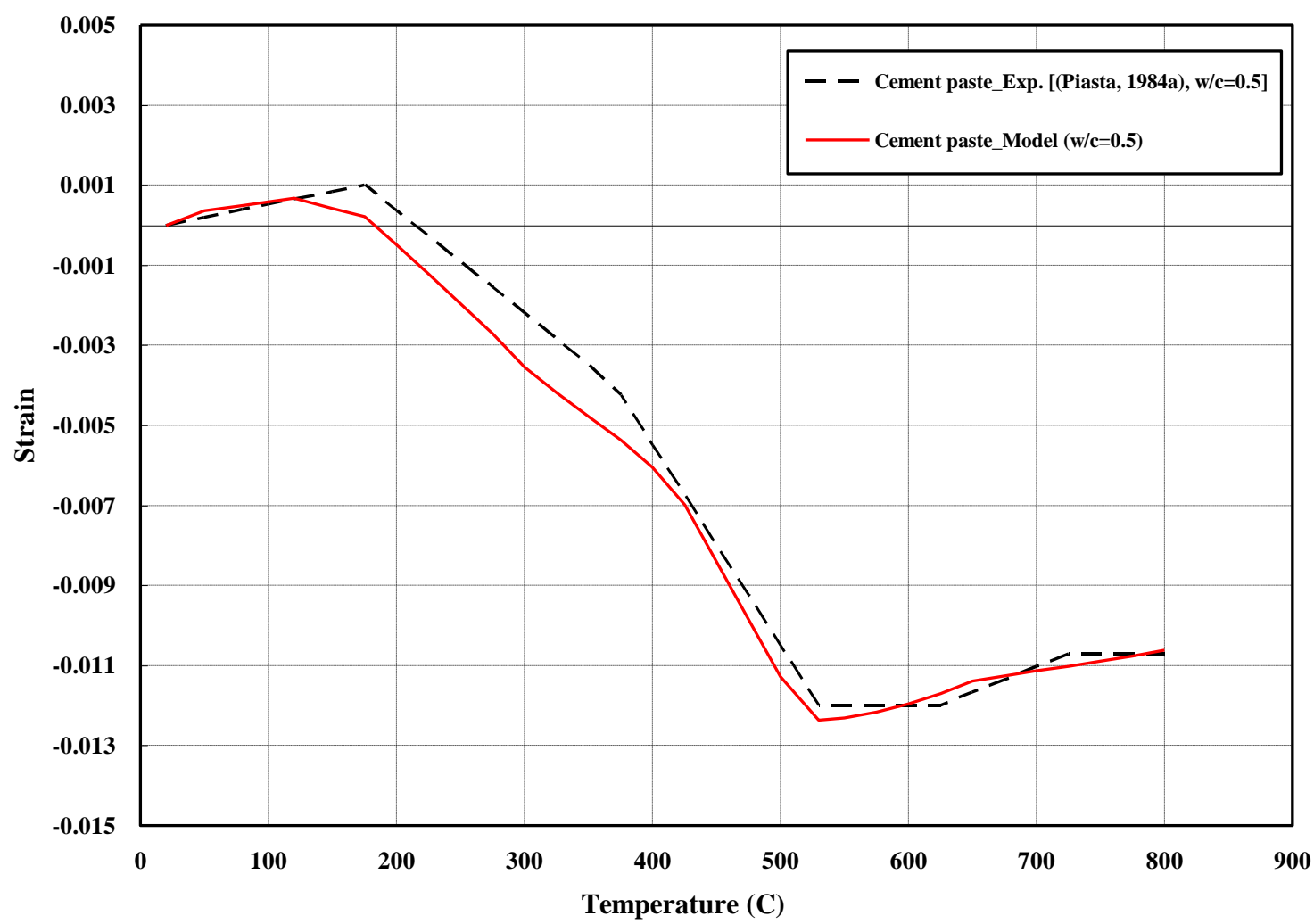

Figure 7. Comparison between model and experimental data for cement paste

Table 8 is a summary for the thermal strain functions according to temperature rage of cement paste with $\mathrm{w} / \mathrm{c}=0.5$ obtained from the model.

Table 8. Summary for thermal strain functions of cement paste from model $(\mathrm{w} / \mathrm{c}=0.5)$

\begin{tabular}{|c|c|c|}
\hline From model & Temperature & Strain \\
\hline \multirow{12}{*}{$\begin{array}{c}\text { Cement } \\
\text { paste }\end{array}$} & $20^{\circ} \mathrm{C}<\mathrm{T} \leq 50^{\circ} \mathrm{C}$ & $\varepsilon=1.17667 \cdot 10^{-5} T-2.35333 \cdot 10^{-4}$ \\
\hline & $50^{\circ} \mathrm{C}<\mathrm{T} \leq 120^{\circ} \mathrm{C}$ & $\varepsilon=4.62857 \cdot 10^{-6} T+1.21571 \cdot 10^{-4}$ \\
\hline & $120^{\circ} \mathrm{C}<\mathrm{T} \leq 175^{\circ} \mathrm{C}$ & $\varepsilon=-8.60 \cdot 10^{-6} T+1.709 \cdot 10^{-3}$ \\
\hline & $175^{\circ} \mathrm{C}<\mathrm{T} \leq 300^{\circ} \mathrm{C}$ & $\varepsilon=-3.0032 \cdot 10^{-5} T+5.4596 \cdot 10^{-3}$ \\
\hline & $300^{\circ} \mathrm{C}<\mathrm{T} \leq 400^{\circ} \mathrm{C}$ & $\varepsilon=-2.493 \cdot 10^{-5} T+3.929 \cdot 10^{-3}$ \\
\hline & $400^{\circ} \mathrm{C}<\mathrm{T} \leq 425^{\circ} \mathrm{C}$ & $\varepsilon=-3.80 \cdot 10^{-5} T+9.157 \cdot 10^{-3}$ \\
\hline & $425^{\circ} \mathrm{C}<\mathrm{T} \leq 500^{\circ} \mathrm{C}$ & $\varepsilon=-5.712 \cdot 10^{-5} T+1.7283 \cdot 10^{-2}$ \\
\hline & $500^{\circ} \mathrm{C}<\mathrm{T} \leq 530^{\circ} \mathrm{C}$ & $\varepsilon=-3.66 \cdot 10^{-5} T+7.023 \cdot 10^{-3}$ \\
\hline & $530^{\circ} \mathrm{C}<\mathrm{T} \leq 575^{\circ} \mathrm{C}$ & $\varepsilon=4.66667 \cdot 10^{-6} T-1.48483 \cdot 10^{-2}$ \\
\hline & $575^{\circ} \mathrm{C}<\mathrm{T} \leq 625^{\circ} \mathrm{C}$ & $\varepsilon=9.32 \cdot 10^{-6} T-1.7524 \cdot 10^{-2}$ \\
\hline & $625^{\circ} \mathrm{C}<\mathrm{T} \leq 650^{\circ} \mathrm{C}$ & $\varepsilon=1.264 \cdot 10^{-5} T-1.9599 \cdot 10^{-2}$ \\
\hline & $650^{\circ} \mathrm{C}<\mathrm{T} \leq 800^{\circ} \mathrm{C}$ & $\varepsilon=5.08667 \cdot 10^{-6} T-1.46893 \cdot 10^{-2}$ \\
\hline
\end{tabular}




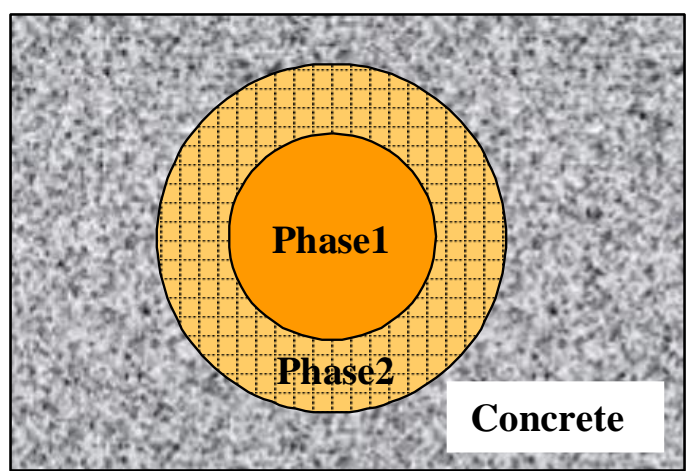

Phase 1: Aggregates

Phase 2: Cement paste

(From effective medium

considering phases)

Phase 3: Concrete

(Effective homogeneous medium)

Figure 8. Arrangement of phases in concrete

In calculation of thermal strain of concrete from model, Figure 8 shows that aggregates are surrounded by cement paste. The bulk moduli of cement paste according to temperature increase are calculated using Equation (10) with the volume fractions of phases according to temperature increase from the multi-scale stoichiometric model. In application of Equation (9) to calculate thermal expansion of concrete from the model, shear modulus of cement paste is calculated using the mixture theory of Equation (18).

$$
G_{c p}=\sum_{i=1}^{N} f_{i} \cdot G_{i}
$$

In which, $G_{i}$ and $f_{i}$, which changed with temperature increase, are the shear modulus and the volume fraction for $\mathrm{C}_{3.4} \mathrm{~S}_{2} \mathrm{H}_{3}, \mathrm{CH}$, Monosulfate, $\mathrm{C}_{3.4} \mathrm{~S}_{2}$, and $\mathrm{CaO}$ calculated at cement paste level.

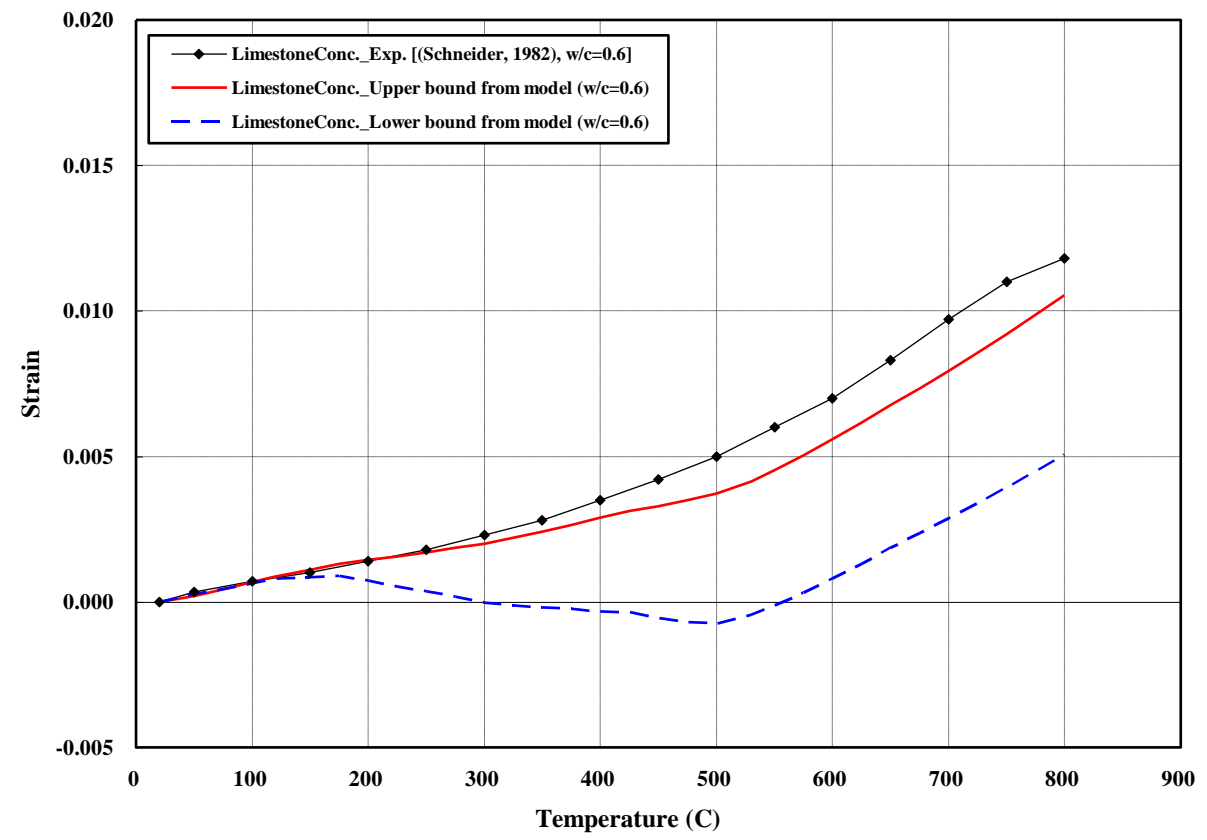

Figure 9. Comparison between model and experimental data for limestone concrete 


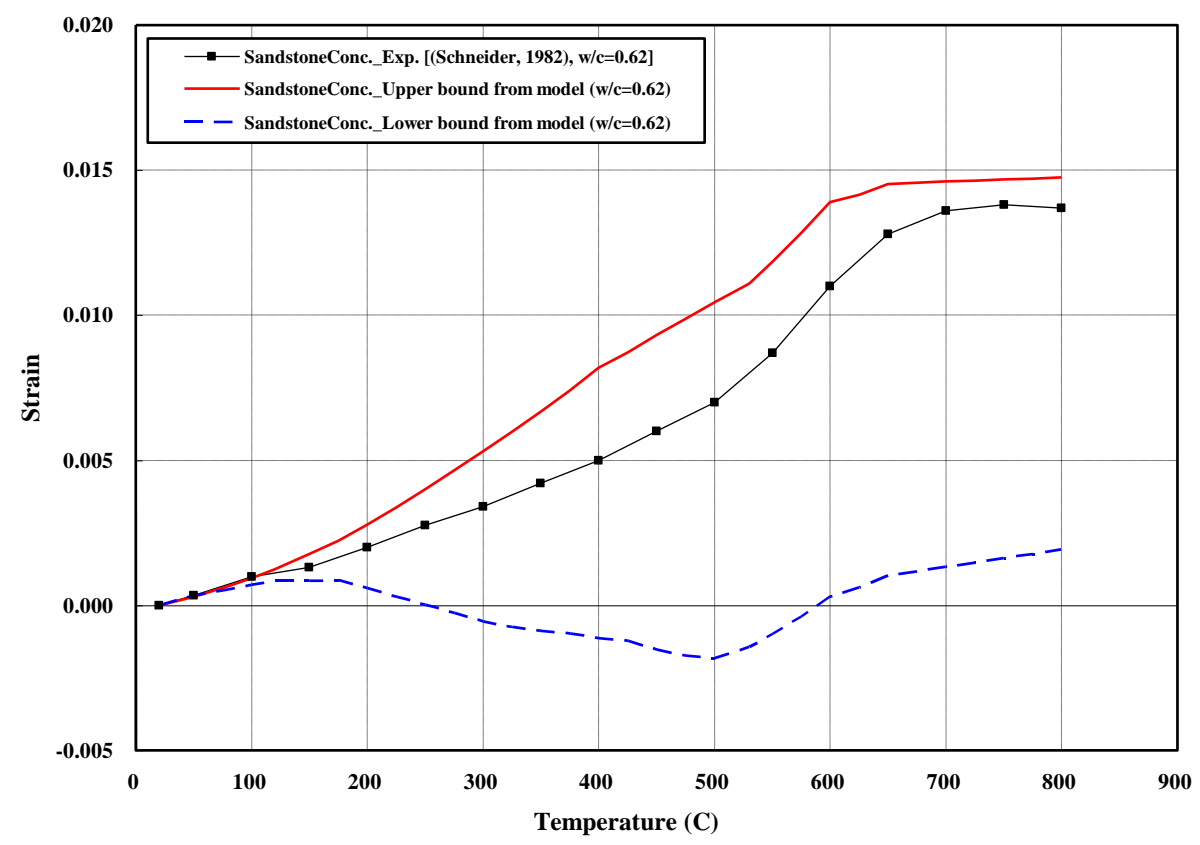

Figure 10. Comparison between model and experimental data for sandstone concrete

In the ranges of material properties of aggregates given in Table 6, the upper and lower bounds for strains of limestone concrete and sandstone concrete are shown in Figure 9 and Figure 10 with the test data, respectively. The functions, which are based on the test data of Soles and Geller [19], in Table 7 were used as the thermal strains of the aggregates in the model. The test data by Scheider [6] were plotted in Figure 9 and Figure 10. The test samples by Scheider [6] were sleeve shaped with diameter $80 \mathrm{~mm}$ and height $300 \mathrm{~mm}$. The samples were cured for 750 days under the condition of $65 \%$ relative humidity at a temperature of $20 \pm 2{ }^{\circ} \mathrm{C}$ after water curing for 7 days. The test data for the sandstone concrete is contained between the upper and lower bound from the model. While the test data of the limestone concrete is a little higher than the upper bound from the model. The upper bounds from the model are matched relatively well with the test results.

The rocks have different material properties due to different chemical portions in the rocks, even if they have the same name, the thermal strains are also different from each other. In the model, the test data of the aggregates by Soles and Geller[19] was used to calculate the thermal strains of limestone concrete and sandstone concrete. The test data for the concretes used to compare with the model is from Scheider[6]. When aggregates and concrete (containing the same aggregates) undergo the same test conditions, and the material properties of the aggregates are given, it is likely that the proposed model predicts the thermal expansion of concrete reasonably.

\section{Conclusions}

(1) At cement paste level, the model, obtained by a combination of the multi-scale composite model and the multi-scale stoichiometric model, was compared with test results from Piasta[3], and satisfactorily predicted them.

(2) The test data for the sandstone concrete was contained in the upper bound and lower bound from the model. While the test data for limestone concrete was a little higher than the upper bound from the model.

(3) At concrete level, the upper bounds from the model were matched relatively well with test results by Scheider[6].

(4) The thermal deformation of the aggregates used is an important factor in the thermal deformation of concrete because aggregates occupy about $70 \%$ of the total volume of concrete. When aggregates and concrete (containing the same aggregates) undergo the same test conditions, and the material 
properties of the aggregates are given, it is likely that the proposed model predicts the thermal expansion of concrete reasonably.

Author Contributions: Conceptualization, Jaesung Lee and Yunping $\mathrm{X}$; Formal analysis, Seungcho Yang; Methodology, Yunping Xi; Writing - original draft, Jaesung Lee and Seungcho Yang; Writing - review \& editing, Jaesung Lee.

Funding: This research received no external funding

Acknowledgments: This research was supported by a grant(18AUDP-B100356-04) from Architecture \& Urban Development Research Program funded by Ministry of Land, Infrastructure and Transport of Korean government.

Conflicts of Interest: The authors declare no conflict of interest.

\section{References}

1. Harmathy, T.J.J.o.M. Thermal properties of concrete at elevated temperatures. 1970.

2. Harada, T.; Takeda, J.; Yamane, S.; Furumura, F.J.S.P. Strength, elasticity and thermal properties of concrete subjected to elevated temperatures. 1972, 34, 377-406.

3. Piasta, J.; Sawicz, Z.; Rudzinski, L.J.M.e.C. Changes in the structure of hardened cement paste due to high temperature. 1984, 17, 291-296.

4. Piasta, J.J.M.e.C. Heat deformations of cement paste phases and the microstructure of cement paste. 1984, 17, 415-420.

5. Cruz, C.R.; Gillen, M.J.F.; materials. Thermal expansion of Portland cement paste, mortar and concrete at high temperatures. 1980, 4, 66-70.

6. Schneider, U.; Herbst, H.J.D.A.f.S. Permeability and porosity of concrete at high temperature. 1989, 2352.

7. Wang, X.-S.; Wu, B.-S.; Wang, Q.-Y.J.C.; Research, C. Online SEM investigation of microcrack characteristics of concretes at various temperatures. 2005, 35, 1385-1390.

8. Bastami, M.; Aslani, F.; ESMAEILNIA, O.M. High-temperature mechanical properties of concrete. 2010.

9. Hager, I.J.B.o.t.P.A.o.S.T.S. Behaviour of cement concrete at high temperature. 2013, 61, 145-154.

10. $\mathrm{Xi}, \mathrm{Y}$;; Jennings, H.M.J.M.; Structures. Shrinkage of cement paste and concrete modelled by a multiscale effective homogeneous theory. 1997, 30, 329.

11. Lee, J.; Xi, Y.; Willam, K.; Jung, Y.J.C.; Research, C. A multiscale model for modulus of elasticity of concrete at high temperatures. 2009, 39, 754-762.

12. Christensen, R.; Lo, K.J.J.o.t.M.; Solids, P.o. Solutions for effective shear properties in three phase sphere and cylinder models. 1979, 27, 315-330.

13. Christensen, R.M. Mechanics of composite materials; Courier Corporation: 2012.

14. Hervé, E.; Zaoui, A.J.E.j.o.m.A.S. Modelling the effective behavior of nonlinear matrix-inclusion composites. 1990, 9, 505-515.

15. Okajima, S.J.M.S.t., Okayama University, Japan. Study of thermal properties of rock-forming minerals. 1978.

16. Mindess, S.; Young, J. Concrete Civil Engineering and Engineering Mechanics Series. Prentice-Hall, New Jersey, USA: 1986.

17. Mehta, P.K. Concrete. Structure, properties and materials. 1986.

18. Velez, K.; Maximilien, S.; Damidot, D.; Fantozzi, G.; Sorrentino, F.J.C.; Research, C. Determination by nanoindentation of elastic modulus and hardness of pure constituents of Portland cement clinker. 2001, $31,555-561$. 
19. Soles, J.A.; Geller, L.B. Experimental studies relating mineralogical and petrographic features to the thermal piercing of rocks; Queen's Printer: 1963. 